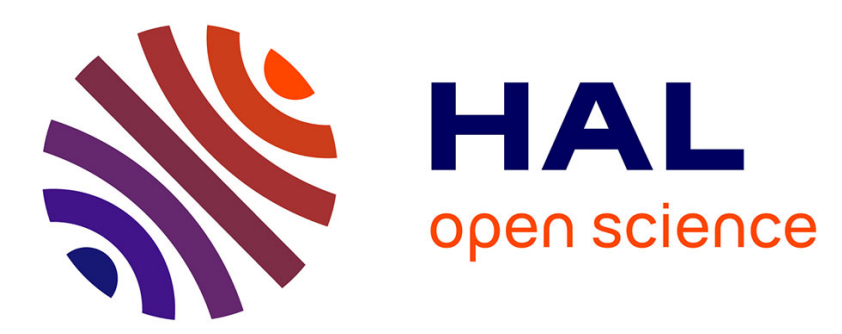

\title{
Switchable heteroleptic mononuclear iron(II) complexes as versatile molecular building block
}

Cherif Baldé, Nicolas Paradis, Cédric Desplanches, Guillaume Chastanet

\section{To cite this version:}

Cherif Baldé, Nicolas Paradis, Cédric Desplanches, Guillaume Chastanet. Switchable heteroleptic mononuclear iron(II) complexes as versatile molecular building block. European Journal of Inorganic Chemistry, 2018, 2018 (19), pp.2004-2010. 10.1002/ejic.201800053 . hal-01798679

\section{HAL Id: hal-01798679 \\ https://hal.science/hal-01798679}

Submitted on 24 May 2018

HAL is a multi-disciplinary open access archive for the deposit and dissemination of scientific research documents, whether they are published or not. The documents may come from teaching and research institutions in France or abroad, or from public or private research centers.
L'archive ouverte pluridisciplinaire HAL, est destinée au dépôt et à la diffusion de documents scientifiques de niveau recherche, publiés ou non, émanant des établissements d'enseignement et de recherche français ou étrangers, des laboratoires publics ou privés. 


\title{
Switchable heteroleptic mononuclear iron(II) complexes as versatile molecular building block
}

\author{
Baldé C. ${ }^{1}$, Paradis N. ${ }^{2}$, Desplanches C. ${ }^{2}$, Chastanet G. ${ }^{2}$ \\ ${ }^{1}$ Laboratoire de Chimie et Physique (LCPM), Université Assane Seck de Ziguinchor, BP : 523 Zinguinchor, Sénégal \\ ${ }^{2}$ CNRS, Univ. Bordeaux, ICMCB, UMR 5026, F-33600 Pessac, France
}

\begin{abstract}
A series of photoswitchable precursors based on $\left[\mathrm{Fe}(\mathrm{NCX})_{2} \mathrm{~L}\left(\mathrm{~L}^{\prime}\right)_{2}\right]$, where $\mathrm{X}=\mathrm{S}$ or $\mathrm{Se}, \mathrm{L}$ is a bidentate ligand (phenanthroline or bipyrimidine), and L' a monodentate ligand such as a pyridine or picoline derivative, were synthesized and their spin crossover (SCO) properties investigated in detail. The thermal and light-induced magnetic properties of a family of $\left[\mathrm{Fe}(\mathrm{NCS})_{2} \mathrm{~L}(\mathrm{py})_{2}\right][\mathrm{py}=$ pyridine and $\mathrm{L}=$ bipyrimidine $(\mathbf{1})$ or phenanthroline (phen) (2)] is reported. The $\left[\mathrm{Fe}(\mathrm{NCX})_{2}(\right.$ phen $\left.)\left(\mathrm{L}^{\prime}\right)_{2}\right]$ compounds were further explored by changing the counteranion from NCS- to $\mathrm{NCSe}^{-}$(3) or by replacing pyridine with 4-picoline (4) or 4ethylpyridine (5). Complexes 1-4 exhibit thermal and lightinduced SCO, while 5 remains in the high-spin state. The kinetics governing the photoinduced back-conversion was investigated for compounds 2 and 4 . Complex 2 exhibits LIESST relaxation kinetics involving strongly cooperative (sigmoidal) behavior, whereas complex 4 displays a stretched exponential shape, typical for broad distributions of relaxation times. These results are discussed on the basis of the steric hindrance due to bulkiness and the electronic influence of the substituent effects on the magnetic and photomagnetic properties of mononuclear iron(II) complexes.
\end{abstract}




\section{Introduction}

Molecules are increasingly considered for information processing and sensing applications.1,2 Among them, spin crossover (SCO) molecules able to change their electronic configuration on application of external stimuli such as temperature, pressure, light, and electric field have received great interest for the construction of molecular devices with optical switching and/or magneto-optical storage properties.-11 Of these, by far the majority are pseudo-octahedral $3 \mathrm{~d}^{6}$ iron(II) complexes, which can be switched between a diamagnetic low-spin (LS) electronic configuration state $\mathrm{t}_{2 \mathrm{~g}}{ }^{6} \mathrm{e}^{0}\left({ }^{1} \mathrm{~A}_{1 \mathrm{~g}}, S=0\right)$ and a paramagnetic high-spin (HS) electronic state $t_{2 g}{ }^{4} e_{g}{ }^{2}\left({ }^{5} T_{2 g}, S=2\right)$. The LS $\rightleftarrows$ HS conversion is accompanied by profound changes in all properties that depend on the distribution of the $3 \mathrm{~d}$ valence electrons. Besides the most obvious change of magnetic properties, ${ }^{12}$ a reversible change of color, ${ }^{13}$ refractive index, ${ }^{14}$ electrical conductivity, ${ }^{15}$ luminescence, ${ }^{16}$ nonlinear optical behavior, ${ }^{17 a}$ and mechanical properties $^{17 b}$ may accompany SCO. Therefore, much research has focused on the improvement of such property changes, especially the ability to observe the switching at room temperature.

Ligand design has been the focus of much attention. ${ }^{18-22}$ It has allowed generation of highly cooperative spin-transition iron(II) complexes to promote hysteretic effects. Apart from the design of extended architectures, the synthesis of polynuclear complexes bearing several iron(II) centers is an attractive way to promote intramolecular cooperativity at the molecular level.23, 24, 24f, 25 One interest in such polynuclear systems lies in the possible interplay between photoswitching and magnetic exchange, which can give rise to unusual magnetic behavior. ${ }^{26}$ To achieve this synergy, bridging ligands able to mediate magnetic exchange are obviously required, but the use of photoswitchable units is also crucial.

We present herein the properties of several photoswitchable precursors based on $\left[\mathrm{Fe}(\mathrm{NCX})_{2} \mathrm{~L}\left(\mathrm{~L}^{\prime}\right)_{2}\right]$, where $\mathrm{X}=\mathrm{S}$ or Se, $\mathrm{L}$ is a bidentate ligand (phenanthroline or bipyrimidine), and L' a monodentate ligand such as a pyridine or picoline derivative. The monodentate ligand is labile and can be substituted by other ligands with bridging abilities. This approach has already been used for binuclear complexes $23 a, b, 27$ and may offer other opportunities to obtain polynuclear architectures.

Iron(II) complexes $\left[\mathrm{Fe}(\mathrm{NCS})_{2} \mathrm{~L}\left(\mathrm{~L}^{\prime}\right)_{2}\right]$ with $\mathrm{L}^{\prime}=$ pyridine $(\mathrm{py})$ and $\mathrm{L}=$ bipyrimidine $(\mathrm{bpym})(\mathbf{1})$ or phenanthroline (phen) (2) were obtained and their thermo- and photoswitching were investigated. We further explored the $\left[\mathrm{Fe}(\mathrm{NCX})_{2}\right.$ (phen) $\left.\left(\mathrm{L}^{\prime}\right)_{2}\right]$ compounds by changing the counteranion from NCS- to $\mathrm{NCSe}^{-}$(3) or by replacing pyridine with 4-picoline (4-pico) (4) or 4-ethylpyridine (4-ethylpy) (5). Since one or two of the labile monodentate ligands can be substituted, we focused our attention on the influence of the alkyl-substituted pyridine ligand on magnetic and photomagnetic properties by determining systematically the $T_{1 / 2}$ and T(LIESST) values. Results are discussed on the basis of a study on the kinetics governing the photoinduced back-conversion. The main objective is to demonstrate that, by playing with the nature of the substituent and its position, it is possible to tune the thermal and lightinduced properties. This could be seen as a first attempt to create a library of switchable precursors usable for the elaboration of polynuclear architectures. The aim is to synthesize switchable building blocks, independently of their own crystal structure. For some of these precursors, chemical functionalization was studied. Indeed, recent studies have shown that the electronic influence of a substituent on a coordinated metal ion depends on its position on the ligand framework.18-21

\section{Results and Discussion}

The $\left[\mathrm{Fe}(\mathrm{NCX})_{2}(\mathrm{py})_{2} \mathrm{~L}\right]$ Precursors

$\left[\mathrm{Fe}(\mathrm{NCS})_{2}(\mathrm{py})_{2}(\mathrm{bpym})\right] 0.25 \mathrm{py}(\mathbf{1})$ and $\left[\mathrm{Fe}(\mathrm{NCS})_{2}(\mathrm{py})_{2}\right.$ (phen)] 0.5py (2) were synthesized in the 1990s.27b The structure of $\mathbf{1}$ has been solved at room temperature and shows a trans configuration of the pyridine ligands, and we expected a similar conformation for compound 2, as depicted in Scheme 1. IR spectra suggest that both compounds $\mathbf{1}$ and $\mathbf{2}$ have a cis configuration of the NCS- ligands (Supporting 
Information). The thermal dependence of the $\chi_{M} T$ product, in which $\chi_{M}$ is the molar magnetic susceptibility, was already reported. It decreases on cooling, with a slightly more abrupt character for 1 than for 2 (Figure 1). The thermal SCO temperatures are $114 \mathrm{~K}$ for $\mathbf{1}$ and $104 \mathrm{~K}$ for $\mathbf{2 . 2 7 \mathrm { b }}$

Light-induced SCO was attempted, according to the LIESST (light-induced spin-state trapping) process. ${ }^{28}$ Irradiation into appropriate ligand-field $(\mathrm{d}-\mathrm{d})$ or charge-transfer absorption bands of the LS state with visible or near-infrared light can induce trapping of the metastable HS state. Experimentally, the photoinduced SCO was investigated by using a SQUID magnetometer coupled to a continuous-wave optical source, following the classical recording of the T(LIESST) temperature: After photoirradiation at $10 \mathrm{~K}$, the light was switched off and the temperature increased at $0.3 \mathrm{~K} \mathrm{~min}^{-1}$. On warming, the metastable state relaxes to the LS state ${ }^{29}$ and, if this relaxation is efficient, the photoinduced state is erased. This leads to the determination of a limiting temperature value T(LIESST). ${ }^{30}$ This procedure was followed for compounds 1 and 2 (Figure 1).

For both compounds, a quantitative LS $\rightarrow$ HS photoconversion was achieved under irradiation at $10 \mathrm{~K}$ with a laser diode emitting at $650 \mathrm{~nm}$. After irradiation, $\chi_{M} T$ first increases on warming in the dark from 10 to $30 \mathrm{~K}$ due to zero-field splitting of the HS iron(II) ion. ${ }^{31}$ Like the thermal SCO, the T(LIESST) curves are very similar with a difference of $8 \mathrm{~K}$ in the T(LIESST) values, determined by the minimum of the derivative $\mathrm{d}\left(\chi_{\mathrm{M}} T\right) / \mathrm{d} T$ versus $T$ (62 $\mathrm{K}$ for 1 and $54 \mathrm{~K}$ for 2 ). The abrupt character of the thermal SCO, which is more pronounced in $\mathbf{1}$ than in $\mathbf{2}$, is recovered in the T(LIESST) curves, whereby that of $\mathbf{1}$ is more abrupt than that of 2 . This can be seen in the full width at half-maximum of $6 \mathrm{~K}$ for 2 as opposed to only $3.5 \mathrm{~K}$ for $\mathbf{1}$.

Both molecules are thus interesting for use as photoswitchable precursors for polynuclear architectures. However, compound $\mathbf{1}$ is much more difficult to handle than compound $\mathbf{2}$. Indeed, the bipyrimidine ligand acts as a bridging ligand, and a binuclear complex or 1D chains can be obtained. ${ }^{23 a}$, 27 Complex 2 offers more possible chemical functionalizations to tune the switching properties. The most obvious one, which is also valid for $\mathbf{1}$, is to replace the thiocyanate anion by a selenocyanate ion.

[Fe(NCSe) ${ }_{2}(\mathrm{py})_{2}$ (phen)] 0.5py (3) could be easily obtained (see Experimental Section), and IR spectra suggested a cis configuration of the NCSe- ligands (Supporting Information). Figure 2 shows the magnetic and photomagnetic properties of 3 . The $\chi_{\mathrm{M}} \mathrm{T}$ product of $3.29 \mathrm{~cm}^{3} \mathrm{~K} \mathrm{~mol}^{-1}$ at $300 \mathrm{~K}$ is in agreement with HS iron(II) ions. On cooling, a decrease in $\chi_{M} T$ occurs to reach $0.09 \mathrm{~cm}^{3} \mathrm{~K} \mathrm{~mol}^{-1}$ at $10 \mathrm{~K}$. This almost complete SCO shows a similar abruptness to that of $\mathbf{2}$, but at higher temperature. Such increase of $T_{1 / 2}$, from $104 \mathrm{~K}$ for 2 to $173 \mathrm{~K}$ for 3 on substitution of NCS- by NCSe-, is well documented, as both the ligand field and the vibrational modes are affected by such change. ${ }^{32}$ Upon $650 \mathrm{~nm}$ irradiation, incomplete LS $\rightarrow$ HS photoconversion is observed (ca. $50 \%$ ). This is coherent with the increase of $T_{1 / 2}$, since, according to the inverse energy-gap law, the higher the thermal SCO temperature, the shorter the photoinduced HS state lifetime.14 This is perfectly reflected in the T(LIESST) curve, which is very gradual, with an apparent T(LIESST) value of $18 \mathrm{~K}$. This demonstrates an efficient HS $\rightarrow$ LS relaxation process in 3.

Compounds 1-3 are thus potential building blocks having switchable properties useful for the construction of polynuclear architectures. From the chemical point of view, the phenanthroline derivatives are easier to handle and several substitutions can be performed to tune the properties.

The $\left[\mathrm{Fe}(\mathrm{NCS})_{2} \mathrm{~L}_{2}{ }_{2}\right.$ (phen)] Precursors

Starting from compound 2, several chemical modifications can be made, either on the phenanthroline or on the pyridine ligands. In this work, we focused on substituted pyridine ligands (Scheme 2). Compounds $\left[\mathrm{Fe}(\mathrm{NCS})_{2}(4 \text {-pico })_{2} \text { (phen)] (4) and [Fe(NCS) }\right)_{2}(4 \text {-ethylpy })_{2}($ phen $\left.)\right]$ (5) were thus obtained. IR spectra suggested that 4 and 5 also have a cis configuration of the NCS- ligands (Supporting Information). 
The magnetic properties of 4 and 5 were measured (Figure 3). For $\mathbf{4}$, on cooling, the $\chi_{M} T$ value remains approximately constant down to $150 \mathrm{~K}\left(3.05 \mathrm{~cm}^{3} \mathrm{~mol}^{-1} \mathrm{~K}\right)$, at which point the magnetic signal gradually decreases to reach $0.2 \mathrm{~cm}^{3} \mathrm{~K} \mathrm{~mol}^{-1}$ in the temperature range $150-10 \mathrm{~K}$. In the warming mode, the $\chi_{\mathrm{M}} T$ product of 4 smoothly increases and the magnetic data perfectly correspond to those obtained in the cooling mode, that is, complete gradual SCO occurs with $T_{1 / 2}=112 \mathrm{~K}$ without thermal hysteresis. For $\mathbf{5}$, on cooling from room temperature to $30 \mathrm{~K}$, the $\chi_{M} T$ value of 3.5 remains constant, indicative of the HS iron(II) form. The rapid decrease of $\chi_{\mathrm{M}} T$ below $30 \mathrm{~K}$ is most probably due to the zero-field splitting of the HS iron(II) ion. ${ }^{31}$

The effect of light irradiation on compounds 4 was studied by the T(LIESST) procedure. Under $650 \mathrm{~nm}$ irradiation, an increase of $\chi_{M} T$ was observed, but with less efficiency than in 2 . The $\chi_{M} T$ product first increases on warming in the dark from 10 to $30 \mathrm{~K}$ due to zero-field splitting of the HS iron(II) ion. ${ }^{31}$ Above $30 \mathrm{~K}, \chi_{\mathrm{M}} T$ decreases sharply and the T(LIESST) value is estimated to be $54 \mathrm{~K}$ (Figure 4, inset). This value is identical to that of 2 . This agrees with the fact that the thermal SCO temperatures of the two compounds are almost the same.

The dynamics of the LIESST relaxation of the photoinduced HS fraction $\gamma_{\text {HS }}$ (the fraction of spin centers in the sample that is HS) was investigated and compared for $\mathbf{2}$ and $\mathbf{4}$ as a function of temperature. The $\gamma_{\mathrm{HS}}$ value is deduced from $\left[\left(\chi_{\mathrm{M}} T\right)_{h v}-\left(\chi_{\mathrm{M}} T\right)_{\mathrm{LS}}\right] /\left[\left(\chi_{\mathrm{M}} T\right)_{\mathrm{HS}}-\left(\chi_{\mathrm{M}} T\right)_{\mathrm{LS}}\right]$, where $\left(\chi_{\mathrm{M}} T\right)_{h v}$ is the maximum value reached after irradiation, $\left(\chi_{M} T\right)_{\text {LS }}$ the value of the initial LS state, and $\left.\chi_{\mathrm{M}} T\right)_{\mathrm{HS}}$ the value recorded at room temperature for a fully HS state. Figure $5 \mathrm{a}$ and b show the kinetics recorded for 2 and 4 in the 40-56 K temperature range. For 2 the relaxation curves obviously deviate from single-exponential and were simulated according to Hauser's self-acceleration model [Equations 1, 2, and 3]. ${ }^{29}$ Cooperativity plays a key role in the relaxation here. Thus, the height of the activation barrier to LIESST relaxation changes as a function of $\gamma_{\mathrm{HS}}$, and the relaxation rate $k_{\mathrm{HL}}^{*}\left(T, \gamma_{\mathrm{HS}}\right)$ depends exponentially on both $\gamma_{\mathrm{HS}}$ and $T$ [Equations 3 and 4$]$, where $a(T)\left(=E_{\mathrm{a}}^{*} / k_{\mathrm{B}} T\right)$ is the acceleration factor.

$$
\begin{aligned}
& \frac{\partial \gamma_{H S}}{\partial t}=-k_{H L}^{*} \gamma_{H S} \\
& k^{*}{ }_{\mathrm{HL}}\left(T, \gamma_{\mathrm{HS}}\right)=k_{\mathrm{HL}}(T) \exp \left[\alpha(T)\left(1-\gamma_{\mathrm{HS}}\right)\right] \\
& k_{H L}(T)=k_{\infty} \cdot \exp \left(-E_{a} / \mathrm{kB}_{\mathrm{B}} T\right) \\
& \frac{\partial \gamma_{H S}}{\partial t}=-\gamma_{H S}\left\{k_{0}+k_{\infty} \exp \left(-E_{a} / k_{B} T\right)\right\} \cdot \exp \left[\alpha(T)\left(1-\gamma_{H S}\right)\right]
\end{aligned}
$$

This procedure yielded the solid lines shown in Figure 5a. From these simulations, the apparent activation energy $E_{\mathrm{a}}$, and the pre-exponential factor $k_{\infty}$, of the activated region can be calculated from a linear regression analysis of $\ln k_{\mathrm{HL}}(T)$ versus $1 / T$ (Figure $7 \mathrm{a}$, inset). These values were determined to be $E_{\mathrm{a}}=350 \mathrm{~cm}^{-1}, E_{\mathrm{a}}^{*}=65 \mathrm{~cm}^{-1}$, and $k_{\infty}=10 \mathrm{~s}^{-1}$ for 2 .

The HS $\rightarrow$ LS relaxation curves for 4 exhibit a clear stretched exponential behavior (Figure $5 b$ ) with a time dependence of the HS fraction, which is fast on a short timescale and slows down at longer timescales. Such stretched exponential behaviors have already been mentioned for disordered systems, such as an iron(II) SCO complex dispersed in a polymer matrix ${ }^{33}$ or organized on a surface by the Langmuir-Blodgett technique. ${ }^{34}$ To reproduce these types of curves, Hauser et al. ${ }^{33}$ used a distribution of 
relaxation rates at a given temperature with a Gaussian distribution of the activation energy. The solid lines in Figure $5 \mathrm{~b}$ results from the least-square fits of the relaxation data with a stretched exponential model. A good fit of the data was found with a Gaussian distribution having a standard deviation of 35 $\mathrm{cm}^{-1}$. An Arrhenius plot gave dynamical parameters of $E_{\mathrm{a}}=345 \mathrm{~cm}^{-1}$ and $k_{\infty}=20 \mathrm{~s}^{-1}$ for 4 . The almost identical dynamical parameters of 2 and 4 lead to globally constant T(LIESST) values of the two complexes around $54 \mathrm{~K}$.

A good way to test the validity of the kinetic parameters obtained from the simulation of the relaxation kinetics is to reproduce the experimental T(LIESST) curves. The procedure used for that carefully takes into account both time and temperature dependences of the relaxation, and combines the quantum mechanical tunneling and the thermally activated regions, according to Equation 4 . The rate constant $k_{0}$ characterizes the relaxation in the quantum tunneling region, and is estimated as an upper limit from the last complete kinetics recorded at the lowest temperature. Figures $1 \mathrm{~b}$ and 4 show the calculated $T$ (LIESST) curves deduced from the kinetic parameters obtained for $\mathbf{2}$ and $\mathbf{4}$. The T(LIESST) curves were calculated by taking into account the anisotropy of the HS iron(II) ion in octahedral surroundings. This phenomenon, known as zero-field splitting, is associated with the spin-orbit coupling between the ground state and the excited state in zero applied magnetic field. For an iron(II) ion in HS configuration, the $S=2$ ground state is split into three levels. The magnetic contribution of each state is determined by their energy separation and their thermal population. This has been discussed in detail by Létard et al..$^{35}$ The perfect agreement between the experimental and the simulated T(LIESST) curves (with $g=2.2$ and $D=14 \mathrm{~cm}^{-1}$ for 2 , and $g=2.15$ and $D=16 \mathrm{~cm}^{-1}$ for 4 ) provides some confidence in the kinetic parameters determined in this study.

The results obtained here regarding the photoinduced state confirm that T(LIESST) is controlled by $E_{a}$ and $k_{\infty}$, which suggests that the relaxation mechanism of a metastable state is mainly governed at the molecular scale (the crystal packing acts as a perturbation), while the thermal SCO regime is driven by both ligand-field and crystal-packing effects.

\section{Conclusion}

We have reported the thermal and light-induced magnetic properties of a family of $\left[\mathrm{Fe}(\mathrm{NCX})_{2}\left(\mathrm{~L}^{\prime}\right)_{2} \mathrm{~L}\right]$ compounds: $\left[\mathrm{Fe}(\mathrm{NCS})_{2}(\mathrm{py})_{2}(\mathrm{bpym})\right](\mathbf{1}),\left[\mathrm{Fe}(\mathrm{NCS})_{2}(\mathrm{py})_{2}(\mathrm{phen})\right](\mathbf{2}),\left[\mathrm{Fe}(\mathrm{NCSe})_{2}\left(\mathrm{py}^{\prime}\right)_{2}\right.$ (phen)] (3), [Fe(NCS) $)_{2}$ (4-picoline) $)_{2}$ (phen)] (4), and [Fe(NCS) ${ }_{2}$ (4-ethylpyridine) ${ }_{2}$ (phen)] (5). Complexes 1-4 exhibit thermal and light-induced SCO, whereas 5 remains HS. Whereas going from 2 to 4 by exchange of $\mathrm{H}$ by $\mathrm{CH}_{3}$ in the 4-position of the pyridine ligand does not seem to strongly affect the SCO properties, except for the cooperative character of the transition, going to 5 with a $\mathrm{C}_{2} \mathrm{H}_{5}$ substituent drastically affects the magnetic behavior. The first hypothesis to explain this behavior is that this substitution lowers the ligand-field strength. This could be correlated to the studies conducted by Gütlich and co-workers on [Fe(Y-phen) $\left.)_{3}\right] \mathrm{X}_{2}$ complexes. ${ }^{36}$ It has been illustrated for this family that exchange of $\mathrm{H}$ for $\mathrm{CH}_{3}$ in either the 2- or 9-position of the three phen ligands lowers the ligand-field strength due to steric hindrance, whereby the metal-donor atom distance is elongated, and the LS behavior of $\left[\mathrm{Fe}(\mathrm{phen})_{3}\right] \mathrm{X}_{2}$ turns to SCO behavior of the tris(2- $\mathrm{CH}_{3}$-phen) complex. In addition, if both the 2- and 9-positions of the three phen ligands are substituted by $\mathrm{CH}_{3}$, the steric hindrance is even stronger and lowers the ligand-field strength further, and this results in HS behavior of the tris[2,9- $\left.\left(\mathrm{CH}_{3}\right)_{2}\right]$ complex down to very low temperatures. ${ }^{36}$ This hypothesis would deserve a detailed investigation of the ligand-field strength, for example, by means of measurements in solution (NMR or magnetism) to avoid the packing effects and to look solely at the isolated complexes. Indeed, the cooperative thermal SCO regime is affected by the ligand substituent, and this could be linked to the increase of the ligand size, which pushes the molecules apart from each other. Moreover, introduction of substituents can drastically change the vibrational entropic contribution contributing to quenching the thermal SCO. Therefore, a combination of steric hindrance 
due to bulkiness, electronic influence of the substituent on the basicity of the coordinating $\mathrm{N}$ atom, and crystal-packing effects can affect the SCO behavior. ${ }^{37}$

Substitution in the 2-position of the pyridine or phenanthroline ligand induces high steric strain that prevent any coordination to the metal site. Clearly, from the perspective of using such molecules as molecular building blocks for polynuclear architectures, studies on functionalization of the phenanthroline ligand could afford chemical levers to tune the switching properties of the resulting molecule. In addition, the study of sterically constrained complexes would give insight into the influence of the coordination-sphere distortion on the stability of the light-induced HS state. These investigations are currently under way.

\section{Experimental section}

\section{Synthesis}

General: All syntheses were carried out under nitrogen.

[Fe(NCS) $)_{2}(\text { py })_{2}($ bpym)] 025py (1): Complex 1 was prepared as described earlier by Erickson et al.38 but with slight modification: hydrated iron(II) perchlorate was replaced by $\mathrm{FeSO}_{4} \cdot 7 \mathrm{H}_{2} \mathrm{O}$. $\mathrm{FeSO}_{4} \cdot 7 \mathrm{H}_{2} \mathrm{O}(0.278$ $\mathrm{g}, 1 \mathrm{mmol})$ was treated with $\mathrm{KSCN}(0.194 \mathrm{~g}, 2 \mathrm{mmol})$ in dry and freshly distilled methanol $(5 \mathrm{~mL})$. The precipitated $\mathrm{K}_{2} \mathrm{SO}_{4}$ was filtered off, and the solution was added to pyridine $(5 \mathrm{~mL})$. The mixture became yellow after incorporation of pyridine. The mixture was stirred for $30 \mathrm{~min}$ and gradually added to a solution of 2,2'-bipyrimidine $(0.158 \mathrm{~g}, 1 \mathrm{mmol})$ in pyridine $(6 \mathrm{~mL})$. The purple powder formed from the solution was filtered off and dried under vacuum. [Fe(NCS $)_{2}(\text { py })_{2}($ bpym)]: calcd. C 50.23, H 3.42, N 22.74, S 12.62; found C 50.06, H 3.34, N 22.35, S11.83.

[Fe(NCS) ${ }_{2}$ (py) ${ }_{2}$ (phen)] 0.5py (2): $\mathrm{FeSO}_{4} \cdot 7 \mathrm{H}_{2} \mathrm{O}(0.278 \mathrm{~g}, 1 \mathrm{mmol})$ was treated with $\mathrm{KSCN}(0.194 \mathrm{~g} 2 \mathrm{mmol})$ in dry and freshly distilled methanol $(5 \mathrm{~mL})$. The precipitated $\mathrm{K}_{2} \mathrm{SO}_{4}$ was filtered off, and the solution was added to pyridine $(5 \mathrm{~mL})$. The mixture became yellow after incorporation of pyridine. The mixture was stirred for $30 \mathrm{~min}$ and gradually added to a solution containing 1,10-phenanthroline $(0.180 \mathrm{~g} 1$ $\mathrm{mmol})$ in pyridine $(6 \mathrm{~mL})$. The purple powder formed from the solution was filtered off and dried under vacuum. [Fe(NCS) $)_{2}(\mathrm{py})_{2}$ (phen)]: calcd. C 57.87, H 3.76, N 16.55, S 11.66; found C 57.61, H 3.72, N 16.54, S 11.83.

[Fe(NCSe) $)_{2}(\text { py })_{2}$ (phen)] 0.5py (3): Complex 3 was obtained by the same synthetic procedure as 2, except that KSCN was replaced by KSeCN $(0.194 \mathrm{~g}, 2 \mathrm{mmol})$. A purple powder was obtained. [Fe(NCSe) ${ }_{2}$ (py) ${ }_{2}$ (phen)]: calcd. C 49.44, H 3.21, N 14.14; found C 49.35, H 3.162, N 13.61.

[Fe(NCS) ${ }_{2}$ (4-pico) ${ }_{2}$ (phen)] (4): Compound 4 was synthesized by the same procedure as used for 2 , except that pyridine was replaced by 4-picoline. The intermediate solution was green/black in color, and the final precipitate was purple. The elemental analysis of $\mathrm{C}, \mathrm{H}, \mathrm{N}, \mathrm{S}$ fit the calculated data. $\mathrm{Fe}(\mathrm{NCS})_{2}(4-$ pico) ${ }_{2}$ (phen)]: calcd. C 59.54, H 4.39, N 15.56, S 10.96; found C 59.18, H 4.49, N 15.2, S 9.50.

[Fe(NCS) ${ }_{2}$ (4-ethylpy) $)_{2}$ (phen)] (5): Compound 5 was synthesized according to the same procedure as used for 2 , by replacing pyridine with 4-ethylpyridine. The intermediate solution was orange in color, and the final precipitate was purple. [Fe(NCS) $)_{2}$ (4-ethylpy) ${ }_{2}$ (phen)]: calcd. C 61.65, H 5.07, N 14.63, S 10.00; found C 61.65, H 5.11, N 14.50, S 10.08 .

IR Spectra: IR spectra were recorded by the standard KBr pellet technique with a Shimadzu IRAffinity-1 FTIR spectrometer. 
Magnetic and Photomagnetic Studies: Magnetic susceptibility data were collected with a Quantum Design MPMS 5 SQUID magnetometer in an applied field of $1 \mathrm{~T}$. All measurements were performed on homogeneous polycrystalline samples in the temperature range 10 to $290 \mathrm{~K}$. Diamagnetic corrections for the sample holder and the material were applied by using Pascal constants. Photomagnetic measurements were performed with a set of photodiodes coupled through an optical fiber to the cavity of a MPMS-55 Quantum Design SQUID magnetometer operating at $2 \mathrm{~T}$. No change in the data due to heating of the sample was noted. The suspended crystalline sample was prepared in a thin layer (ca. 0.1 $\mathrm{mg}$ ) to promote full penetration of the irradiating light. The sample mass was obtained by comparison with the thermal spin transition curve measured on an accurately weighed larger polycrystalline sample. The calculated mass is of course approximate, but the agreement between the bulk and thin-layer magnetic measurements is reasonable, considering that the data correction for such small amounts of sample is challenging. Our previously published standardized method for obtaining LIESST data was followed.30 The sample was first slowly cooled to $10 \mathrm{~K}$, to ensure that potential trapping of HS species at low temperatures did not occur. Irradiation was carried out at a set wavelength, and the power at the sample surface was adjusted to $5 \mathrm{~mW} \mathrm{~cm}^{-2}$. Once photosaturation was reached, irradiation was ceased, the temperature increased at a rate of $0.3 \mathrm{~K} \mathrm{~min}^{-1}$ to about $100 \mathrm{~K}$, and the magnetization measured every $1 \mathrm{~K}$ to determine the $T$ (LIESST) value given by the extreme of the $\mathrm{d} \chi_{\mathrm{M}} T / \mathrm{d} T$ versus $T$ curve for the relaxation. The T(LIESST) value describes the limiting temperature above which the light-induced magnetic high-spin information is erased in a SQUID cavity. In the absence of irradiation, the magnetism was also measured over the temperature range 10-290 K to follow the thermal spin transition and to obtain a low-temperature baseline. In addition to T(LIESST) measurements, kinetic studies were performed by irradiating the sample at $10 \mathrm{~K}$ until photosaturation, and then, under constant irradiation, the sample was warmed to a desired temperature around the T(LIESST) region, irradiation was ceased, and the decay of the magnetization signal was monitored for several hours, or until complete relaxation back to the low-spin baseline.

\section{Acknowledgements}

We thank the Department of Cooperation and Cultural Action Embassy of France to Dakar-Sénégal, the University of Ziguinchor and its Department of Cooperation and Research, the Ministry of Higher Education and Research of Sénégal (Program FIRST and CNDST) and CAMPUS France. This work was also supported by the University of Bordeaux, the Centre National de la Recherche Scientifique (CNRS), the Region Nouvelle Aquitaine and by the LabEx AMADEus (ANR-10-LABX-42) within IdEx Bordeaux (ANR-10-IDEX-03-02), i.e. the Investissements d'Avenir programme of the French government managed by the Agence Nationale de la Recherche. The ANR is also warmly acknowledge (ANR femtomat $\mathrm{n}^{\circ}$ 13-BS04-002).

\section{References}

[1] M. C. Petty, M. R. Bryce and D. Bloor, in: Introduction to Molecular Electronics, Oxford University Press, New York, 1995.

[2] a) J. M. Lehn, Science, 2002, 295, 2400; M. Ruben, U. Ziener, J. M. Lehn, V. Ksenofontov, P. Gütlich and G. B. M. Vaughan, Chem. Eur. J., 2005, 11, 94; b) M. Fujita, D. Oguro, M. Miyazawa, H. Oka, K. Yamaguchi and K. Ogura, Nature, 1995, 378, 469; c) O. M. Yaghi, M. O'Keeffe, N. W. Ockwig, H. K. Chae, M. Eddaoudi and J. Kim, Nature, 2003, 423, 705.

[3] E. Breuning, M. Ruben, J. M. Lehn, F. Renz, Y. Garcia, V. Ksenofontov, P. Gütlich, E. Wegelius and K. Rissanen, Angew. Chem. Int. Ed., 2000, 39, 2504; Angew. Chem., 2000, 112, 2563.

[4] "Spin Crossover in Transition Metal Compounds I-III" in Topics in Current Chemistry, P. Gütlich. H-A. Goodwin (Ed.), Springer-Verlag, Berlin, 2004, vols. 233-235.

[5] Spin-Crossover Materials, Properties and Applications (Ed.: M. A. Halcrow), John Wiley \& Sons, Chichester, 2013.

[6] A. Bousseksou, G. Molnar, L. Salmon and W. Nicolazzi, Chem. Soc. Rev., 2011, 40, 3313.

[7] O. Kahn and C. J. Martinez, Science, 1998, 279, 44.

Cherif Baldé, Nicolas Paradis, Cédric Desplanches, Guillaume Chastanet. Switchable heteroleptic mononuclear iron(II) complexes as versatile molecular building block. European

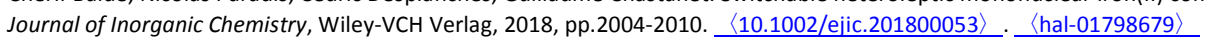


[8] P. Gütlich, A. B. Gaspar and Y. Garcia, Beilstein J. Org. Chem., 2013, 9, 342.

[9] K. S. Kumar and M. Ruben, Coord. Chem. Rev., 2017, 346, 176.

[10] M. D. Manrique-Juarez, S. Rat, L. Salmon, G. Molnar, C. M. Quintero, L. Nicu, H. J. Shepherd and A. Bousseksou, Coord. Chem. Rev., 2016, 308, 395.

[11] P. Guionneau, Dalton Trans., 2014, 43, 382.

[12] a) L. J. Kershaw Cook, R. Mohammed, G. Sherborne, T. D. Roberts, S. Alvarez and M. A. Halcrow, Coord. Chem. Rev., 2015, 289, 2; b) S. Brooker, Chem. Soc. Rev., 2015, 44, 2880; c) R. Bertoni, M. Lorenc, A. Tissot, M.-L. Boillot and E. Collet, Coord. Chem. Rev., 2015, 282-283, 66-76; d) A. B. Gaspar and M. Seredyuk, Coord. Chem. Rev., 2014, 268, 41; e) M. C. Munoz and J. A. Real, Coord. Chem. Rev., 2011, 255, 2068; f) I. A. Gass, S. R. Batten, C. M. Forsyth, B. Moubaraki, C. J. Schneider and K. S. Murray, Coord. Chem. Rev., 2011, 255, 2058; g) B. Weber, Coord. Chem. Rev., 2009, 253, 2432; h) H.-J. Krüger, Coord. Chem. Rev., 2009, 253, 2450; i) I. Krivokapic, M. Zerara, M. L. Daku, A. Vargas, C. Enachescu, C. Ambrus, P. Tregenna-Piggott, N. Amstutz, E. Krausz and A. Hauser, Coord. Chem. Rev., 2007, 251, 364; j) J.-F. Létard, J. Mater. Chem., 2006, 16, 2550.

[13] P. Gütlich and H. A. Goodwin, Top. Curr. Chem., 2004, 233, 1.

[14] A. Hauser, Coord. Chem. Rev., 1991, 111, 275. [15] a) A. Rotaru, I. A. Gural'skiy, G. Molnar, L. Salmon, P. Demont and A. Bousseksou, Chem. Commun., 2012, 48, 4163; b) E. Ruiz, Phys. Chem. Chem. Phys., 2014, 16, 14.

[16] H. J. Shepherd, C. M. Quintero, G. Molnar, L. Salmon and A. Bousseksou in Spin-Crossover Materials, Properties and Applications (Ed. M. A. Halcrow), John Wiley \& Sons, Chichester, 2013, pp. 347-373. [17] a) P. G. Lacroix, I. Malfant, J.-A. Real and V. Rodriguez, Eur. J. Inorg. Chem., 2013, 615; b) M. D. Manrique-Juarez, S. Rat, L. Salmon, G. Molnar, C. M. Quintero, L. Nicu, H. J. Shepherd and A. Bousseksou, Coord. Chem. Rev., 2016, 308, 395.

[18] M. A. Halcrow, Polyhedron, 2007, 26, 3523.

[19] W. Phonsri, D. S. Macedo, K. R. Vignesh, G. Rajaraman, C. G. Davies, G. N. L. Jameson, B. Moubaraki, J. S. Ward, P. E. Kruger, G. Chastanet and K. S. Murray, Chem. Eur. J., 2017, 23, 7052.

[20] M. Halcrow, Crystals, 2016, 6, 58.

[21] H.-L. C. Feltham, A. S. Barltrop and S. Brooker, Coord. Chem. Rev., 2017, 344, 26.

[22] N. Nassirinia, S. Amani, S. J. Teat, O. Roubeau and P. Gamez, Chem. Commun., 2014, 50, 1003. [23] a) J. A. Real, H. Bolvin, A. Bousseksou, A. Dworkin, O. Kahn, F. Varret and J. Zarembowitch, J. Am. Chem. Soc., 1992, 114, 4650; b) J. A. Real, I. Castro, A. Bousseksou, M. Verdaguer, R. Burriel, M. Castro, J. Linares and F. Varret, Inorg. Chem., 1997, 36, 455; c) A. Bousseksou, G. Molnar, J. A. Real and K. Tanaka, Coord. Chem. Rev., 2007, 251, 1822; d) A. B. Gaspar, M. C. Munoz and J. A. Real, J. Mater. Chem., 2006, 16, 2522; e) J. J. M. Amoore, C. J. Kepert, J. D. Cashion, B. Moubaraki, S. M. Neville and K. S. Murray, Chem. Eur. J., 2006, 12, 8220; f) J. J. M. Amoore, S. M. Neville, B. Moubaraki, S. S. Iremonger, K. S. Murray, J.-F. Letard and C. J. Kepert, Chem. Eur. J., 2010, 16, 1973; g) R. J. Archer, C. S. Hawes, G. N. L. Jameson, V. McKee, B. Moubaraki, N. F. Chilton, K. S. Murray, W. Schmitt and P. E. Kruger, Dalton Trans., 2011, 40, 12368; h) X. Cheng, Q. Yang, C. Gao, B.-W. Wang, T. Shiga, H. Oshio, Z.-M. Wang and S. Gao, Dalton Trans., 2015, 44, 11282; i) M. Darawsheh, L. A. Barrios, O. Roubeau, S. J. Teat and G. Aromi, Chem. Eur. J., 2016, 22, 8635; j) D. Fedaoui, Y. Bouhedja, A. Kaiba, P. Guionneau, J.-F. Letard and P. Rosa, Eur. J. Inorg. Chem., 2008, 1022; k) T. Fujinami, K. Nishi, R. Kitashima, K. Murakami, N. Matsumoto, S. lijima and K. Toriumi, Inorg. Chim. Acta, 2011, 376, 136; I) Y. Garcia, C. M. Grunert, S. Reiman, O. van Campenhoudt and P. Gutlich, Eur. J. Inorg. Chem., 2006, 3333; m) Y. Garcia, F. Robert, A. D. Naik, G. Zhou, B. Tinant, K. Robeyns, S. Michotte and L. Piraux, J. Am. Chem. Soc., 2011, 133, 15850; n) A. B. Gaspar, V. Ksenofontov, V. Martinez, M. C. Munz, J. A. Real and P. Gutlich, Eur. J. Inorg. Chem., 2004, 4770; o) C. M. Grunert, S. Reiman, H. Spiering, J. A. Kitchen, S. Brooker and P. Gutlich, Angew. Chem. Int. Ed., 2008, 47, 2997; Angew. Chem., 2008, 120, 3039; p) C. F. Herold, L. M. Carrella and E. Rentschler, Eur. J. Inorg. Chem., 2015, 3632; q) R. W. Hogue, H. L. Feltham, R. G. Miller and S. Brooker, Inorg. Chem., 2016, 55, 4152; r) C. Köhler and E. Rentschler, Eur. J. Inorg. Chem., 2016, 1955; s) G. S. Matouzenko, E. Jeanneau, A. Y. Verat and Y. de Gaetano, Eur. J. Inorg. Chem., 2012, 969; t) E. Milin, S. Belaid, V. Patinec, S. Triki, G. Chastanet and M. Marchivie, Inorg. Chem., 2016, 55, 9038; u) K. Nakano, N. Suemura, K. Yoneda, S. Kawata and S. Kaizaki, Dalton Trans., 2005, 740; v) J. G. Park, I.-R. Jeon and T. D. Harris, Inorg. Chem., 2015, 54, 359; w) M. Quesada, P. de Hoog, P. Gamez, O. Roubeau, G. Aromi, B. Donadieu, C. Massera, M. Lutz, A. L. Spek 
and J. Reedijk, Eur. J. Inorg. Chem., 2006, 1533.

[24] a) G. Vos, R. A. le Febre, R. A. G. de Graaff, J. G. Haasnoot and J. Reedijk, J. Am. Chem. Soc., 1983, 105, 1682; b) G. Vos, R. A. G. de Graaff, J. G. Haasnoot, A. M. van der Kraan, P. de Vaal and J. Reedijk, Inorg. Chem., 1984, 23, 2905; c) J. J. A. Kolnaar, G. van Dijk, H. Kooijman, A. L. Spek, V. G. Ksenofontov, P. Gutlich, J. G. Haasnoot and J. Reedijck, Inorg. Chem., 1997, 36, 2433; d) M. Thomann, O. Kahn, J. Guilhem and F. Varret, Inorg. Chem., 1994, 33, 6029; e) Y. Garcia, P. Guionneau, G. Bravic, D. Chasseau, J. A. K. Howard, O. Kahn, V. Ksenofontov, S. Reiman and P. Gutlich, Eur. J. Inorg. Chem., 2000, 1531; f) M. Nihei, M. Ui and H. Oshio, Polyhedron, 2009, 28, 1718; g) J. A. Kitchen, G. N. L. Jameson, V. A. Milway, J. L. Tallon and S. Brooker, Dalton Trans., 2010, 39, 7637; h) D. Savard, C. Cook, G. D. Enright, I. Korobkov, T. J. Burchell and M. Murugesu, CrystEngComm, 2011, 13, 5190; i) M. Steinert, B. Schneider, S. Dechert, S. Demeshko and F. Meyer, Angew. Chem. Int. Ed., 2014, 53, 6135; Angew. Chem., 2014, 126, 6249; j) V. Gomez, C. Saenz de Pipaon, P. Maldonado-Illescas, J. C. Waerenborgh, E. Martin, J. Benet-Buchholz and J. R. Galan-Mascaros, J. Am. Chem. Soc., 2015, 137, 11924; k) N. Pittala, F. Thetiot, C. Charles, S. Triki, K. Boukheddaden, G. Chastanet and M. Marchivie, Chem. Commun., 2017, 53, 8356.

[25] a) See ref.3 b) M. Ruben, E. Breuning, J.-M. Lehn, V. Ksenofontov, F. Renz, P. Gutlich and G. B. M. Vaughan, Chem. Eur. J., 2003, 9, 4422; c) M. Nihei, M. Ui, M. Yokota, L. Han, A. Maeda, H. Kishida, H. Okamoto and H. Oshio, Angew. Chem. Int. Ed., 2005, 44, 6484; Angew. Chem., 2005, 117, 6642; d) I. Boldog, F. J. Munoz-Lara, A. B. Gaspar, M. C. Munoz, M. Seredyuk and J. A. Real, Inorg. Chem., 2009, 48, 3710; e) O. Hietsoi, P. W. Dunk, H. D. Stout, A. Arroyave, K. Kovnir, R. E. Irons, N. Kassenova, R. Erkasov, C. Achim and M. Shatruk, Inorg. Chem., 2014, 53, 13070; f) L. J. Kershaw Cook, J. Fisher, L. P. Harding and M. A. Halcrow, Dalton Trans., 2015, 44, 9417; g) B. Schneider, S. Demeshko, S. Dechert and F. Meyer, Angew. Chem. Int. Ed., 2010, 49, 9274; Angew. Chem., 2010, 122, 9461; h) Y.-T. Wang, S.-T. Li, S.-Q. Wu, A.-L. Cui, D.-Z. Shen and H.-Z. Kou, J. Am. Chem. Soc., 2013, 135, 5942; i) R.-J. Wei, Q. Huo, J. Tao, R.-B. Huang and L.-S. Zheng, Angew. Chem. Int. Ed., 2011, 50, 8940; Angew. Chem., 2011, 123, 9102.

[26] a) J.-F. Letard, J. A. Real, N. Moliner, A. B. Gaspar, L. Capes, O. Cador and O. Kahn, J. Am. Chem. Soc., 1999, 121, 10630; b) J.-F. Letard, C. Carbonera, J. A. Real, S. Kawata and S. Kaizaki, Chem. Eur. J., 2009, 15, 4146; c) D.-Y. Wu, O. Sato, Y. Einaga and C.-Y. Duan, Angew. Chem. Int. Ed., 2009, 48, 1475; Angew. Chem., 2009, 121, 1503; d) G. Chastanet, A. B. Gaspar, J. A. Real and J.-F. Letard, Chem. Commun., 2001, 819; e) G. Chastanet, C. Carbonera, C. Mingotaud and J.-F. Letard, J. Mater. Chem., 2004, 14, 3516. [27] a) J. A. Real, A. B. Gaspar, M. C. Munoz, P. Gutlich, V. Ksenofontov and H. Spiering, Top. Curr. Chem., 2004, 233, 167; b) R. Claude, J. A. Real, J. Zarembowitch, O. Kahn, L. Ouahab, D. Grandjean, K.

Boukheddaden, F. Varret and A. Dworkin, Inorg. Chem., 1990, 29, 4442.

[28] S. Decurtins, P. Gütlich, C. P. Kohler, H. Spiering and A. Hauser, Chem. Phys. Lett., 1984, 105, 1. [29] a) A. Hauser, J. Jeftic, H. Romstedt, R. Hinek and H. Spiering, Coord. Chem. Rev. 1999, 190-192, 471; b) A. Hauser, C. Enachescu, M. L. Daku, A. Vargas and N. Amstutz, Coord. Chem. Rev., 2006, 250, 1642. [30] a) J.-F. Létard, P. Guionneau, L. Rabardel, J. A. K. Howard, A. E. Goeta, D. Chasseau and O. Kahn, Inorg. Chem., 1998, 37, 4432. b) See ref.[12]; c) J. F. Létard, P. Guionneau, O. Nguyen, J. Sanchez Costa, S. Marcén, G. Chastanet, M. Marchivie and L. Goux-Capes, Chem. Eur. J., 2005, 11, 4582; d) J.-F. Létard, L. Capes, G. Chastanet, N. Moliner, S. Létard, J. A. Real and O. Kahn, Chem. Phys. Lett., 1999, 313, 115; e) S. Marcen, L. Lecren, L. Capes, H. A. Goodwin and J.-F. Létard, Chem. Phys. Lett., 2002, 358, 87; f) N. Shimamoto, S.-S. Ohkoshi, O. Sato and K. Hashimoto, Inorg. Chem., 2002, 41, 678; g) J.-F. Létard, G. Chastanet, P. Guionneau and C. Desplanches in Spin-Crossover Materials: Properties and Applications (Ed.: M. A. Halcrow), 2013, John Wiley \& Sons, Chichester, p. 475.

[31] O. Kahn, in: Molecular Magnetism, VCH, Weinheim, 1993.

[32] a) L. Capes, J.-F. Létard and O. Kahn, Chem. Eur. J., 2000, 6, 2246; b) N. Moliner, M. C. Muñoz, S. Létard, J.-F. Létard, X. Solans, R. Burriel, M. Castro, O. Kahn and J. A. Real, Inorg. Chim. Acta, 1999, 291, 279. c) See ref.[26]; d) See ref.[26] e) E. Trzop, M. Buron-Le Cointe, H. Cailleau, L. Toupet, G. Molnar, A. Bousseksou, A. B. Gaspar, J. A. Real and E. Collet, J. Appl. Crystallogr., 2007, 40, 158; f) N. O. Moussa, S. Mouri, G. Molnár, K. Tanaka, J. A. Real and A. Bousseksou, J. Inorg. Organomet. Polym., 2008, 18, 195; g) J.-Q. Tao, Z.-G. Gu, T.-W. Wang, Q.-F. Yang, J.-L. Zuo and X.-Z. You, Inorg. Chim. Acta, 2007, 360, 4125. [33] A. Hauser, J. Adler and P. Gütlich, Chem. Phys. Lett., 1988, 152, 468.

[34] J. F. Létard, O. Nguyen, H. Soyer, C. Mingotaud, P. Delhaès and O. Kahn, Inorg. Chem., 1999, 38, 3020. [35] J.-F. Létard, G. Chastanet, P. Guionneau, O. Nguyen, S. Marcen, M. Marchivie, P. Guionneau, D. 
Chasseau and P. Gutlich, Monatsh. Chem., 2003, 134, 165.

[36] a) J. Fleisch, P. Gütlich, K. M. Hasselbach and W. Müller, J. Phys. Colloq., 1974, 6, 659; b) P. Gütlich, A. Hauser and H. Spiering, Angew. Chem. Int. Ed. Engl., 1994, 33, 2024; Angew. Chem., 1994, $106,2109$. [37] G.-A. Craig, J.-S. Costa, O. Roubeau, J.-S. Teat and G. Aromí, Chem. Eur. J., 2012, 18, 11703; M. Halcrow, Chem. Soc. Rev., 2011, 40, 4119.

[38] N. E. Erickson and N. Sutin, Inorg. Chem., 1966, 5, 1834. 


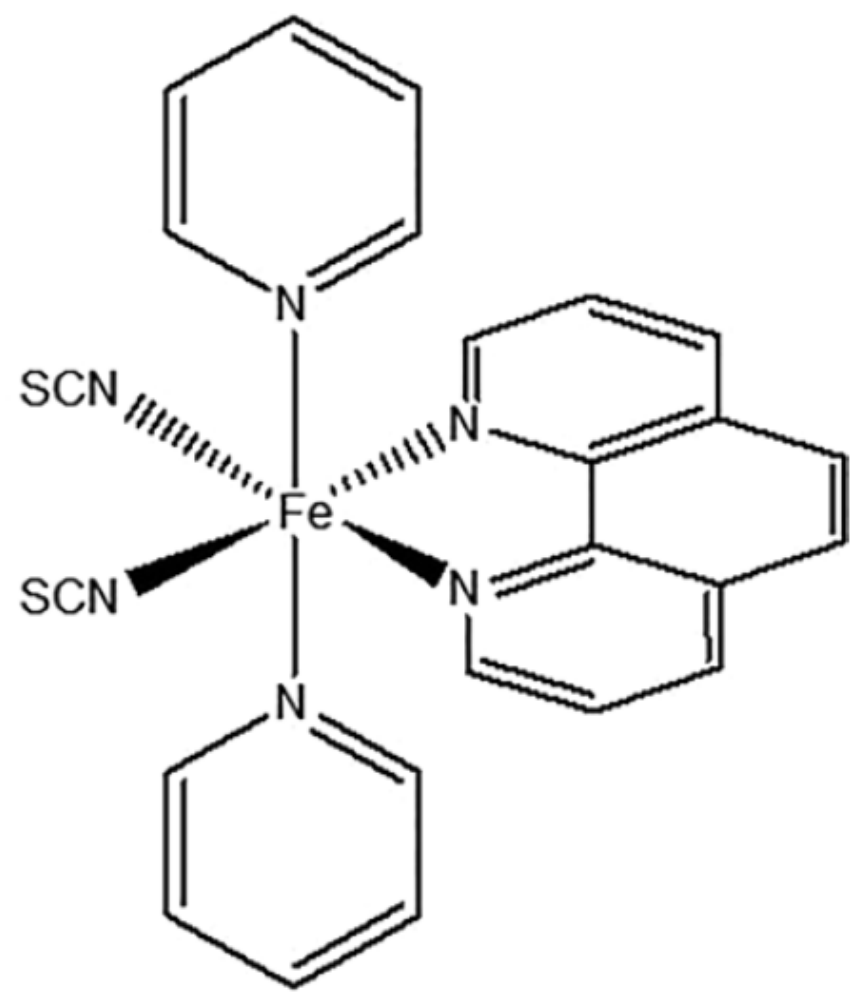

Scheme 1. Schematic representation of the $\left[\mathrm{Fe}(\mathrm{NCS})_{2}(\mathrm{py})_{2}(\mathrm{phen})\right]$ molecule.<smiles>c1ccncc1</smiles>

(py)<smiles>Cc1ccncc1</smiles>

(4-pico)<smiles>CCc1ccncc1</smiles>

(4-ethylpy)

Scheme 2. Ligands $L^{\prime}$ used in this work. 

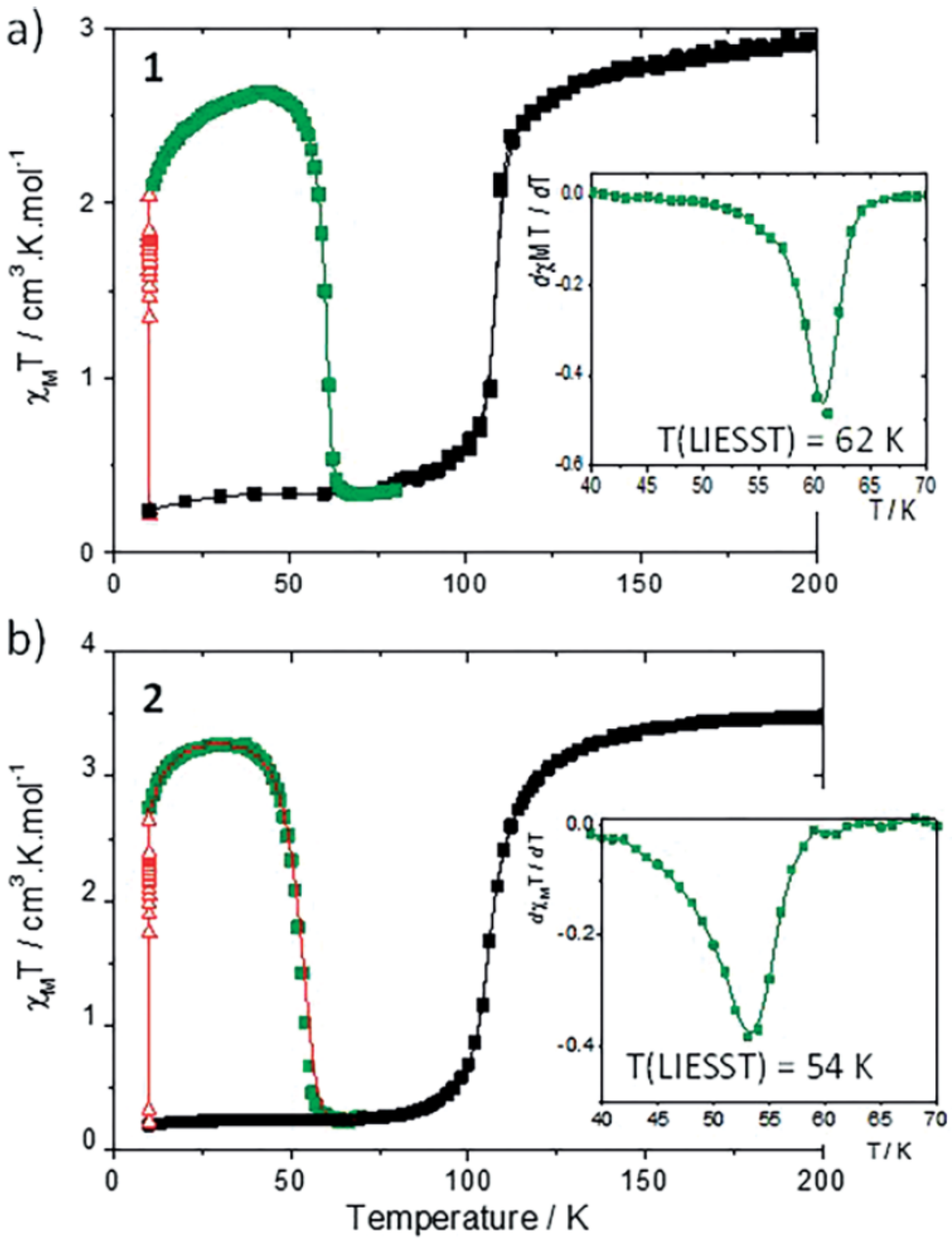

Figure 1. Temperature dependence of $\chi_{M} T$ of 1 (a) and 2 (b): data recorded (black filled squares) without irradiation, (red open triangle) under irradiation at $10 \mathrm{~K}$ and $650 \mathrm{~nm}$, and (green filled squares) $T$ (LIESST) measurements in the warming mode with the laser switched off. The insets show the derivative $\mathrm{d}\left(\chi_{\mathrm{M}} T\right) / \mathrm{d} T$ versus $T$. The red line stands for the simulation of the $T$ (LIESST) curve for 2 (see text). 


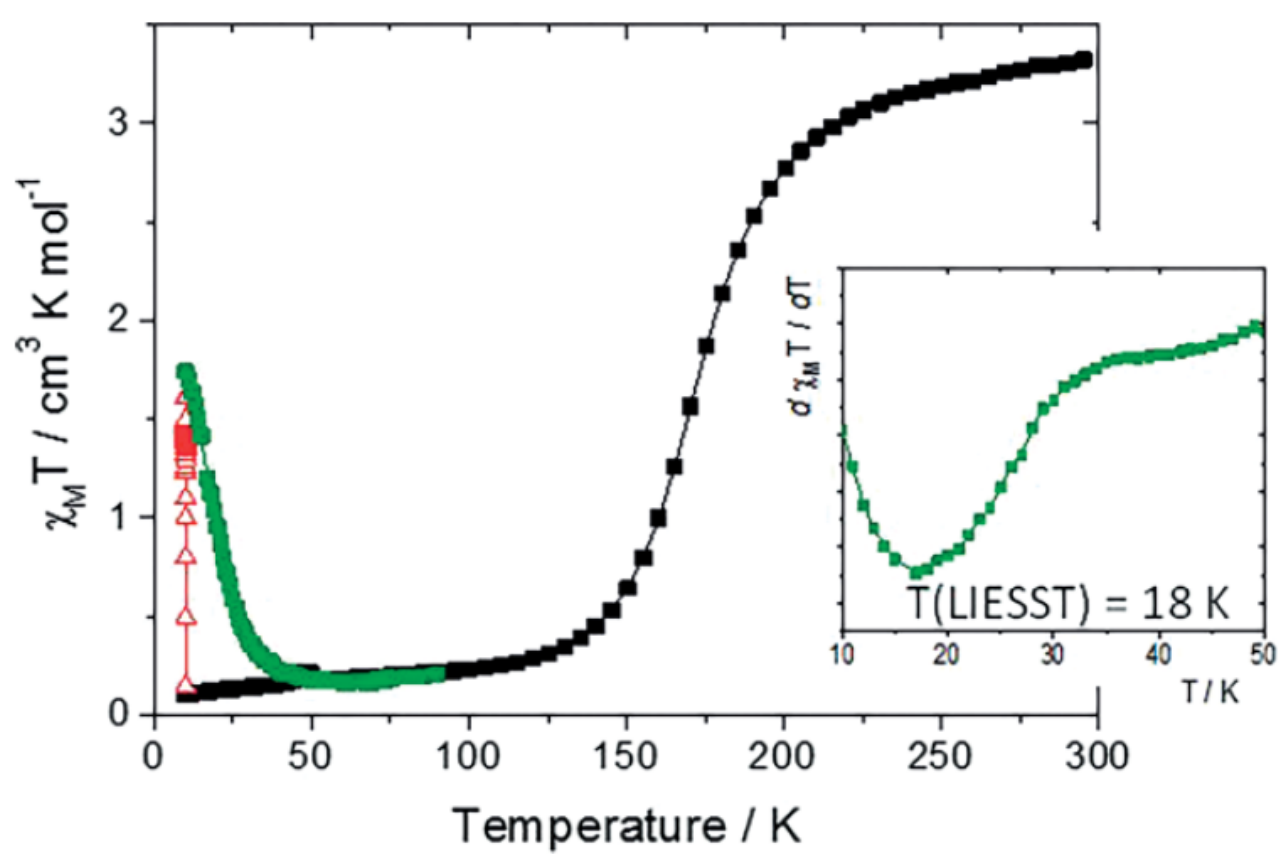

Figure 2. Temperature dependence of $\chi_{\mathrm{M}} T$ for 3: data recorded (black filled squares) without irradiation, (red open triangles) under irradiation at $10 \mathrm{~K}$ and $650 \mathrm{~nm}$, and (green filled squares) T(LIESST) measurement in the warming mode with the laser switched off. The inset shows the derivative $\mathrm{d}\left(\chi_{\mathrm{M}} T\right) / \mathrm{d} T$ versus $T$.

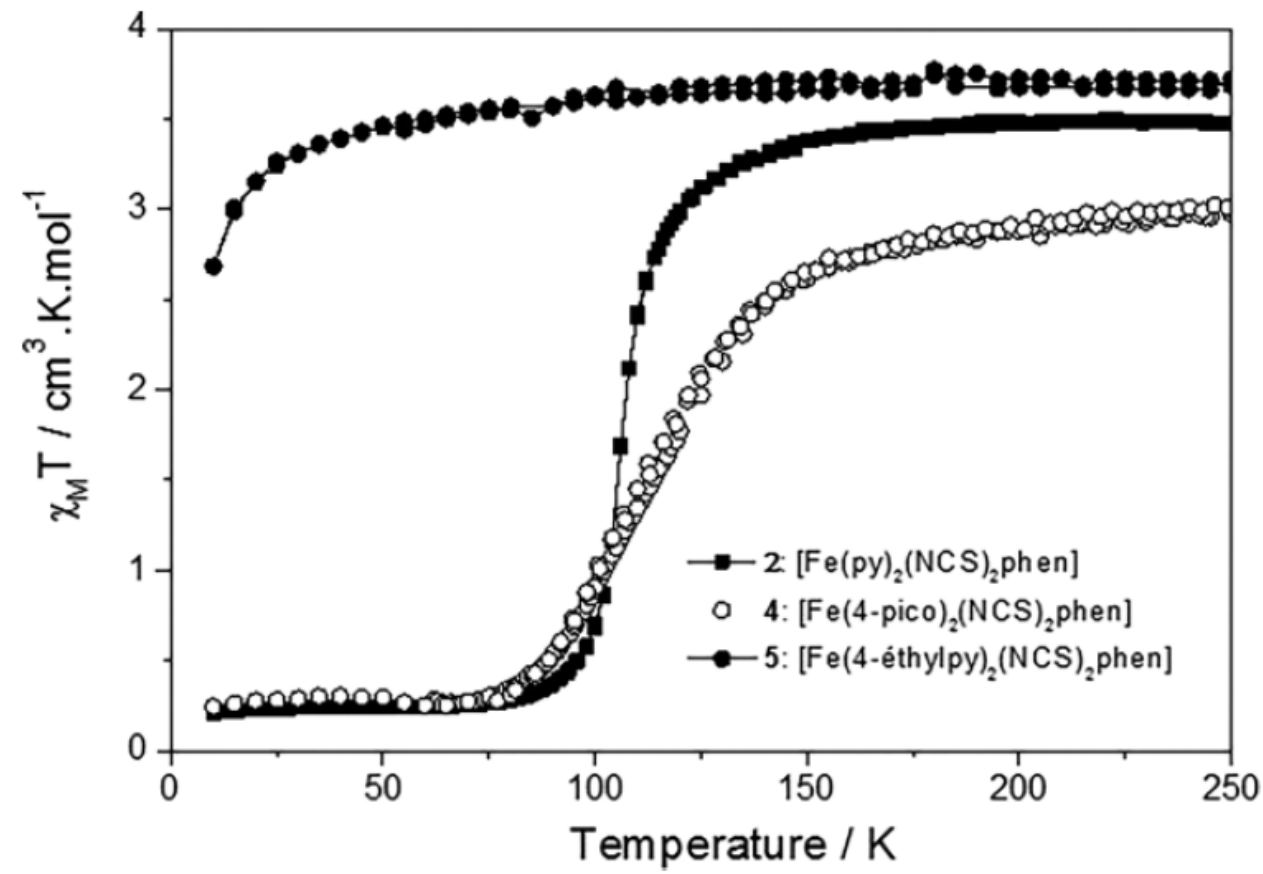

Figure 3. Magnetic properties as function of temperature for $\mathbf{2}, \mathbf{4}$, and $\mathbf{5}$. 


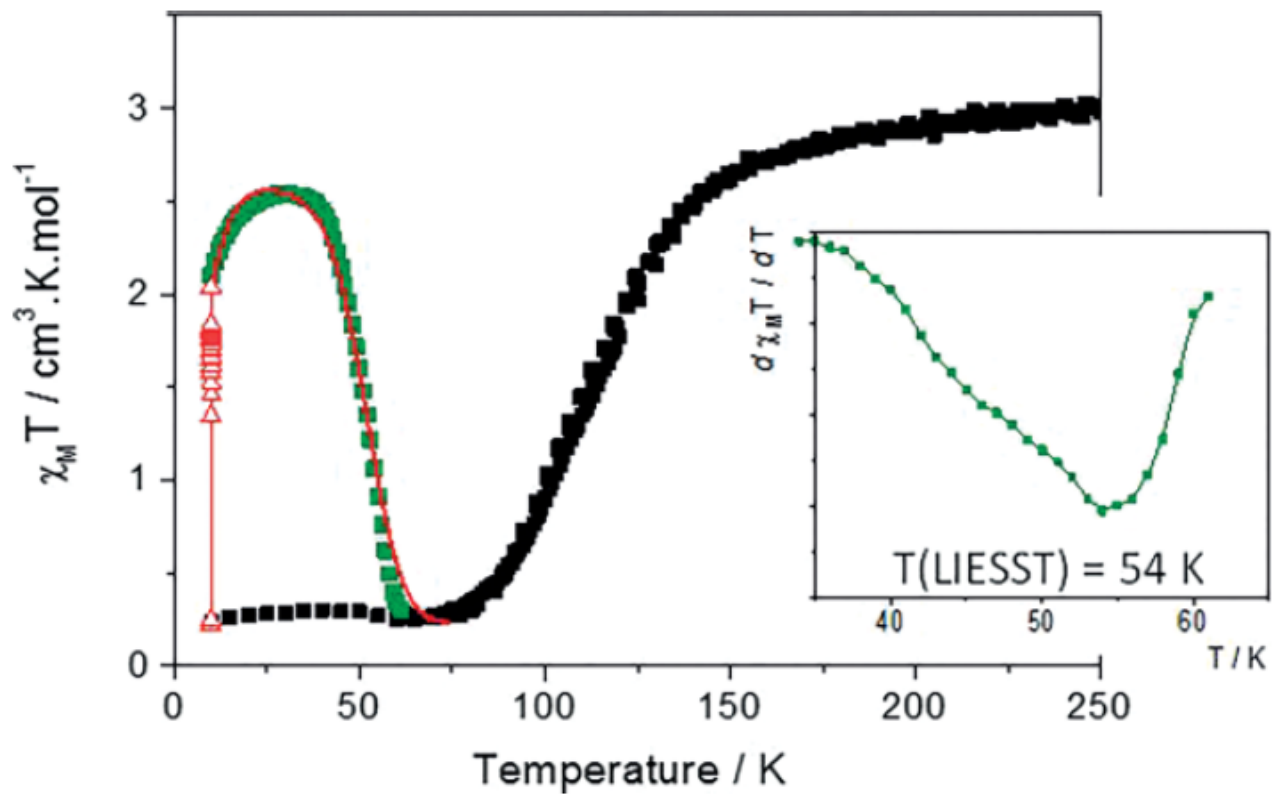

Figure 4. Temperature dependence of $\chi_{\mathrm{M}} T$ for 4 : data recorded (black filled squares) without irradiation, (red open triangles) under irradiation at $10 \mathrm{~K}$ and $650 \mathrm{~nm}$, and (green filled squares) T(LIESST) measurements in the warming mode with the laser switched off. The inset shows the derivative $\mathrm{d}\left(\chi_{\mathrm{M}} T\right) / \mathrm{d} T$ versus $T$. The red line stands for the simulation of the $T$ (LIESST) curve for $\mathbf{4}$, as discussed in the text. 

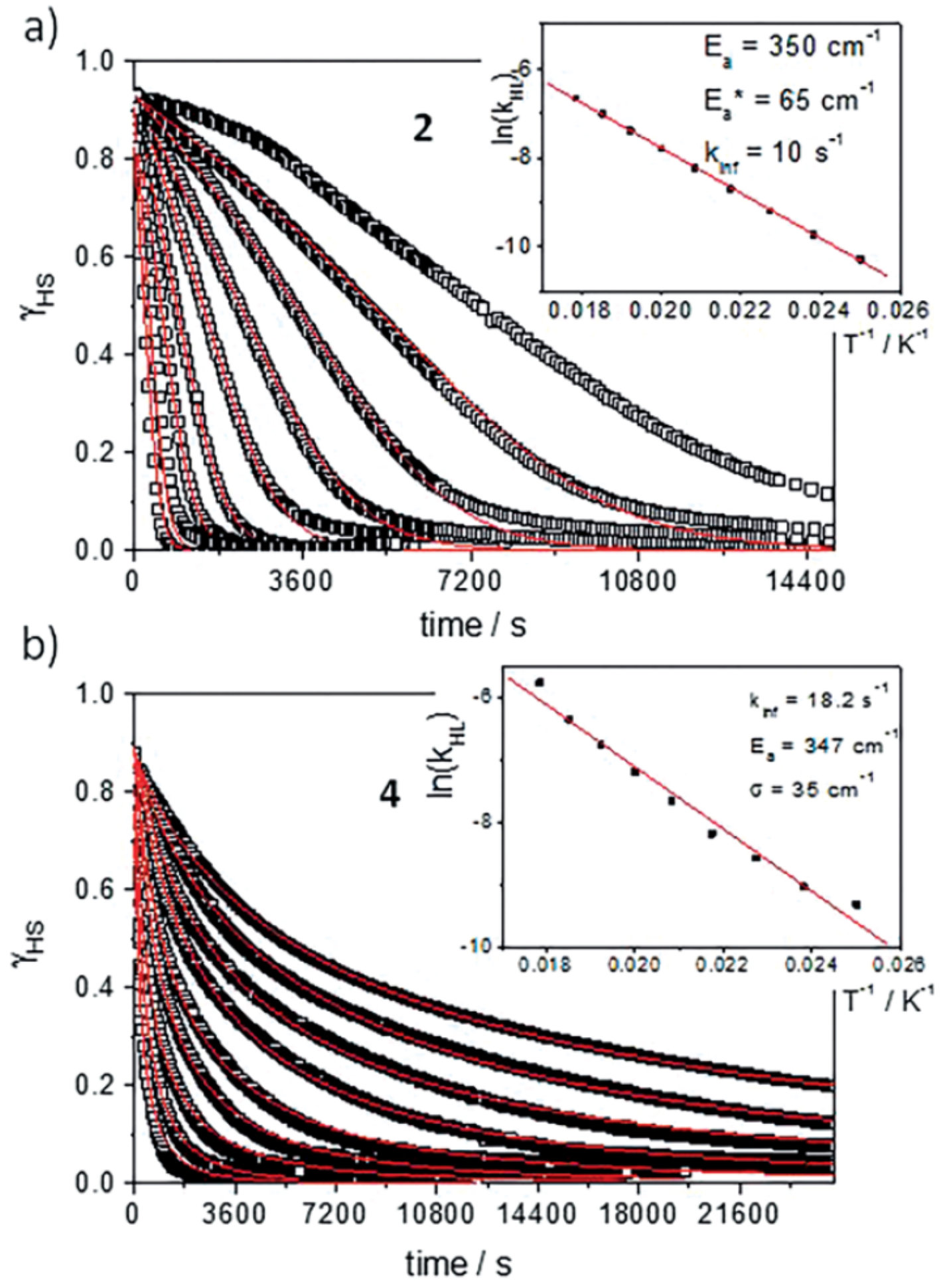

Figure 5. (a) HS $\rightarrow$ LS relaxation as function of temperature for $\mathbf{2}$. The relaxation curves are fitted according to Hauser's sigmoidal law. ${ }^{[29]}$ Inset: Arrhenius plot of $\ln k_{\mathrm{HL}}$ versus $1 / T$. The line represents the best linear fit. (b) HS $\rightarrow$ LS relaxation as function of the temperature for $\mathbf{4}$. For both compounds, kinetics were recorded at each $2 \mathrm{~K}$ between 40 and $56 \mathrm{~K}$. The relaxation curves are fitted according to a Gaussian distribution of activation energy. ${ }^{[33]}$ Inset: Arrhenius plot of $\ln k_{\mathrm{HL}}$ versus $1 / T$. The line represents the best linear fit. 